\title{
HC gp-39 gene is upregulated in glioblastomas
}

\author{
Katherina Shostak ${ }^{\mathrm{a}}$, Vyacheslav Labunskyy $^{\mathrm{a}}$, Vladimir Dmitrenko ${ }^{\mathrm{a}}$, Tatiana Malisheva ${ }^{\mathrm{b}}$, \\ Michail Shamayev ${ }^{\mathrm{b}}$, Vladimir Rozumenko ${ }^{\mathrm{b}}$, Yuriy Zozulyab, Günter Zehetner ${ }^{\mathrm{c}}$, \\ Vadym Kavsan ${ }^{\mathrm{a}, *}$ \\ ${ }^{\mathrm{a}}$ Institute of Molecular Biology and Genetics, 150 Zabolotnogo str., 03143 Kiev, Ukraine \\ ${ }^{\mathrm{b}}$ A.P. Romodanov Institute of Neurosurgery, 32 Manuilskogo str., 04050 Kiev, Ukraine \\ ${ }^{\mathrm{c}}$ Max-Planck Institute for Molecular Genetics, Harnackstrasse 23, 14195 Berlin, Germany
}

Received 16 October 2002; received in revised form 5 April 2003; accepted 15 April 2003

\begin{abstract}
Public databases of the Cancer Genome Anatomy Project were used to quantify the relative gene expression levels in glioblastoma multiforme (GBM) and normal brain by Serial Analysis of Gene Expression (SAGE). Analysis revealed HC gp-39 among the genes with the most pronounced changes of expression in tumor cells. Northern hybridization confirmed the results of computer analysis and showed that enhanced expression of the $\mathrm{HC}$ gp-39 gene was mainly in GBMs and occasionally in anaplastic astrocytomas. Neither SAGE nor Northern analysis revealed the presence of HC gp-39 mRNA in the glioblastoma cell line, thus the detection of increased quantities of this mRNA in GBMs may be associated with activated macrophages. Since the numbers of infiltrating macrophages and small vessel density are higher in glioblastomas than in anaplastic astrocytomas or astrocytomas, the $\mathrm{HC} \mathrm{gp-39} \mathrm{gene} \mathrm{can} \mathrm{be} \mathrm{used} \mathrm{as} \mathrm{a} \mathrm{molecular} \mathrm{marker} \mathrm{in} \mathrm{the} \mathrm{analysis} \mathrm{of} \mathrm{malignant} \mathrm{progression} \mathrm{of}$ astrocytic gliomas.
\end{abstract}

(C) 2003 Elsevier Ireland Ltd. All rights reserved.

Keywords: Brain tumor; Astrocytic gliomas; Glioblastoma multiforme; Electronic subtraction; Differential expression; HC gp-39 gene

\section{Introduction}

Astrocytic gliomas are highly malignant, lethal and the most common glial tumors of the central nervous system. The current picture of the molecular basis of astrocytoma formation and progression presents a complex interplay between multiple genetic events involving non-random anomalies in 1p, 7q, 9p, 10q,

\footnotetext{
* Corresponding author. Tel.: + 380-44-266-3498; fax: +380-44266-0759.

E-mail address: kavsan@imbg.org.ua (V. Kavsan).
}

$11 p, 13 q, 17 p, 19 q, 22 q$ and 22p chromosomes, inactivation of tumor suppressor genes p53 and Rb, and aberrant expression of growth factors EGF, PDGF, FGFs, VEGF and their receptors $[1,2]$.

Obviously, the current knowledge recognizes only a fraction of the biological mechanisms presumed to initiate and promote astrocytic gliomas. Changes in gene expression are important determinants of normal cellular physiology and, if disturbed, directly contribute to abnormal cellular physiology, including cancer. In this context, the identification, cloning and characterization of differentially expressed genes 
can be expected to provide relevant and important insights into the molecular determinants of tumor initiation and progression $[3,4]$.

The facilities of CGAP public databases were used for the comparison of gene expression profiles in glioblastoma multiforme and normal brain by Serial Analysis of Gene Expression (SAGE). The most pronounced overexpression in GBM was observed for the human cartilage HC gp-39 gene. Northern hybridization confirmed the results of computer analysis and showed enhanced expression of the $\mathrm{HC}$ gp-39 gene mainly in GBMs and sometimes in anaplastic astrocytomas.

\section{Materials and methods}

\subsection{Tumor and normal tissue samples}

Samples of astrocytic gliomas, WHO grade II and grade III, GBMs and other types of brain tumors were obtained from the A.P. Romodanov Institute of Neurosurgery (Kiev). Tumors were classified on the basis of review of hematoxilin and eosin stained sections of surgical specimens. World Health Organization (WHO) criteria were used to classify the tumors. Surgical specimens of histologically normal brain tissue adjacent to tumors were used as a source of normal adult human brain RNA. In all, 20 GBMs were analyzed: 17 were de novo tumors and 3 were recurrent tumors progressed from anaplastic astrocytomas (WHO grade III).

\subsection{Electronic subtraction}

Seven SAGE libraries of GBM (GSM696: SAGE_ Duke_GBM_H1110 H1110; GSM765: SAGE_pooled_GBM; GSM700: SAGE_Duke_H247_Hypoxia; GSM701: SAGE_Duke_H247_normal; GSM705: SAGE_Duke_H54_lacZ; GSM704: SAGE_Duke_ H54_EGFRvIII; GSM703: SAGE_Duke_H392) and six SAGE libraries of normal human brain (GSM713: SAGE_Duke_thalamus; GSM676: SAGE_BB542_ whitematter; GSM763: SAGE_normal_pool(6th); GSM695: SAGE_Duke_BB542_normal_cerebellum; GSM761: SAGE_normal_cerebellum; GSM730: SAGE_NHA(5th) were analyzed to compare gene expression in human GBM with that of normal brain by accessing SAGEmap (NCBI web site http://www. ncbi.nlm.nih.gov/SAGE).

The UniGene database of NCBI was searched to obtain the expressed sequence tags (ESTs) containing coding regions of $\mathrm{HC}$ gp-39 mRNA. The EST with GenBank accession number R74158 was selected for further analysis of $\mathrm{HC}$ gp-39 gene expression. The selected cDNA clone (IMAGEp998P09248) was obtained from the Resource Center/Primary DataBase (RZPD) of the German Human Genome Project (Max Planck Institute of Molecular Genetics, Berlin).

\subsection{RNA isolation and northern blot analysis}

Total RNA was isolated from frozen tissues according to Chomczynski and Sacchi [5]. RNA (10 $\mu$ g per lane) was electrophoretically separated in a $1.5 \%$ agarose gel containing $2.2 \mathrm{M}$ formaldehyde and then transferred to a Hybond-N nylon membrane (Amersham Pharmacia Biotech, Austria). ${ }^{32} \mathrm{P}$-labeled probe was produced with RediPrime II kit (Amersham Pharmacia Biotech) using a $1261 \mathrm{bp}$ fragment of HC gp-39 cDNA obtained after digestion of the IMAGEp998P09248 plasmid by Hind III and EcoR I endonucleases. The membrane was hybridized with a ${ }^{32} \mathrm{P}$-labeled HC gp-39 cDNA probe in $50 \%$ formamide, $5 \times \mathrm{SSC}, 5 \times$ Denhardt's solution, $0.1 \% \mathrm{SDS}$ and $100 \mu \mathrm{g} / \mathrm{ml}$ salmon sperm DNA at $42{ }^{\circ} \mathrm{C}$ overnight. Extensive washing was performed: twice with $2 \times \mathrm{SSC}, 0.1 \% \mathrm{SDS}$ for $15 \mathrm{~min}$ at room temperature; once with $2 \times \mathrm{SSC}, 0.1 \% \mathrm{SDS}$ for $30 \mathrm{~min}$ at $65^{\circ} \mathrm{C}$; and finally with $0.2 \times \mathrm{SSC}, 0.1 \% \mathrm{SDS}$ for $30 \mathrm{~min}$ at $65^{\circ} \mathrm{C}$. Subsequently, the membrane was exposed to radiographic film with an intensifying screen at $-70{ }^{\circ} \mathrm{C}$. The membrane was re-hybridized with a ${ }^{32} \mathrm{P}$-labeled human $\beta$-actin cDNA probe as a control of RNA gel loading. Densitometric analysis of hybridization signals was performed by the Scion Image $1.62 \mathrm{c}$ program.

\subsection{Statistical analysis}

The histological grade of each glioma according to the WHO criteria, as well as the patient disease status, was determined for each sample collected. Statistical analysis of data in each group was done using the Student's test. 


\section{Results}

\subsection{Identification of candidate genes differentially expressed in glioblastoma multiforme}

We used the CGAP databases to make the 'electronic subtraction' for many thousands of genes expressed in glioblastoma multiforme and normal brain tissues. As was reported previously by Lal et al. [6], SAGE analysis showed more than 5-fold differences $(P<0.001)$ in the distribution of the tags between GBM and normal brain SAGE libraries for $1 \%$ of the genes analyzed (471 of 47,174 genes).

Although many putative differentially expressed genes were revealed by electronic subtraction, we focused on the ones with the greatest differences in tag distribution since these are likely to be the most biologically important in the tumorogenesis of astrocytic gliomas. The abundance of the tags for human cartilage glycoprotein-39 (HC gp-39) gene was 56fold when the pool of seven GBM SAGE libraries and the pool of six normal brain SAGE libraries were compared. The abundance of the tags for the HC gp-39 gene was higher (148-fold) when the pool of only GSM696 and GSM765 SAGE libraries derived from the original tumors was compared with the same pool of six normal brain SAGE libraries. As can be seen in Table 1, there was no significant difference in the tags for the HC gp-39 gene in GBM cell line SAGE libraries, astrocytomas and some other tumors in comparison with normal brain SAGE libraries.

\subsection{Analysis of differential expression of the $H C$ gp-39 gene by Northern blot hybridization}

Tumor-specific expression of the HC gp-39 gene was verified by Northern blot hybridization of a panel of brain tumor and normal brain tissue RNAs. Northern hybridization showed very high expression levels of the HC gp-39 gene found exclusively in astrocytomas of higher grades. Since only signals corresponding to the main $(1.7 \mathrm{~kb})$ band of $\mathrm{HC} \mathrm{gp}-39$ mRNA were used for the calculations, the overall hybridization signals with GBM samples were even more intensive than is implies in Figs. 1d and 2d, which present the relative expression of the HC gp-39

Table 1

Distribution of the Hs.75184 (GTATGGGCCC) tag for the HC gp-39 gene within human brain tumor and normal brain SAGE libraries

\begin{tabular}{|c|c|c|c|c|c|}
\hline Library name & Source & $\begin{array}{l}\text { Tags per } \\
\text { million }\end{array}$ & & Tag counts & Total tags \\
\hline GSM696: SAGE_Duke_GBM_H1110 & Glioblastoma multiforme & 2782 & & 195 & 70,087 \\
\hline GSM765: SAGE_pooled_GBM & Glioblastoma multiforme & 840 & 0 & 52 & 61,886 \\
\hline GSM700: SAGE_Duke_H247_Hypoxia & Glioblastoma multiforme-cell line & 138 & 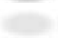 & 10 & 72,031 \\
\hline GSM701: SAGE_Duke_H247_normal & Glioblastoma multiforme-cell line & 131 & 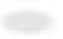 & 8 & 60,663 \\
\hline GSM705: SAGE_Duke_H54_lacZ & Glioblastoma multiforme-cell line & 59 & 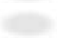 & 4 & 67,236 \\
\hline GSM704: SAGE_Duke_H54_EGFRvIII & Glioblastoma multiforme-cell line & 34 & 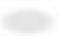 & 2 & 57,400 \\
\hline GSM703: SAGE_Duke_H392 & Glioblastoma multiforme-cell line & 0 & & 0 & 57,582 \\
\hline GSM698: SAGE_Duke_H1043 & Pilocitic astrocytoma grade I & 363 & 0 & 28 & 77,004 \\
\hline GSM2443: SAGE_H408 & Astrocytoma grade II & 174 & 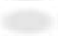 & 14 & 80,265 \\
\hline GSM1498: SAGE_glioma_1150 & Glioma & 31 & $a^{2}$ & 2 & 62,675 \\
\hline GSM2451: SAGE_astrocytoma_H388 & Astrocytoma grade II & 25 & $a^{2}$ & 1 & 38,634 \\
\hline GSM697: SAGE_Duke_H1020 & Anaplastic astrocytoma grade III & 19 & 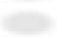 & 1 & 52,479 \\
\hline GSM1732: SAGE_H127 & Astrocytoma & 0 & & 0 & 81,495 \\
\hline GSM715: SAGE_H1126 & Astrocytoma & 0 & & 0 & 17,576 \\
\hline GSM699: SAGE_Duke_H1126 & Astrocytoma & 0 & & 0 & 28,159 \\
\hline GSM689: SAGE_Duke-H988 & Oligodendroglioma & 0 & & 0 & 28,133 \\
\hline GSM713: SAGE_Duke_thalamus & Normal thalamus & 41 & $a^{2}$ & 2 & 48,548 \\
\hline GSM676: SAGE_BB542_whitematter & Normal brain & 21 & $a^{2}$ & 2 & 94,876 \\
\hline GSM763: SAGE_normal_pool(6th) & Normal brain & 0 & & 0 & 63,208 \\
\hline GSM695: SAGE_Duke_BB542_normal_cerebellum & Normal cerebellum & 0 & & 0 & 58,826 \\
\hline GSM761: SAGE_normal_cerebellum & Normal cerebellum & 0 & & 0 & 51,280 \\
\hline GSM730: SAGE_NHA(5th) & Normal brain-astrocyte cell line & 0 & & 0 & 52,261 \\
\hline
\end{tabular}


FB He K NB NB NB NB NBgB GB GB AA GB A GB OA Ep AA A AA OA M MS GB HC gp-39

$\mathbf{a}$

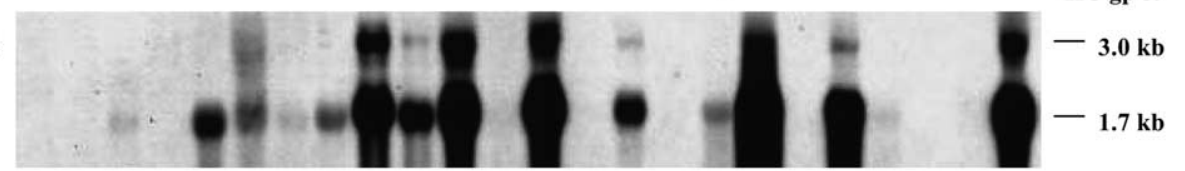

b

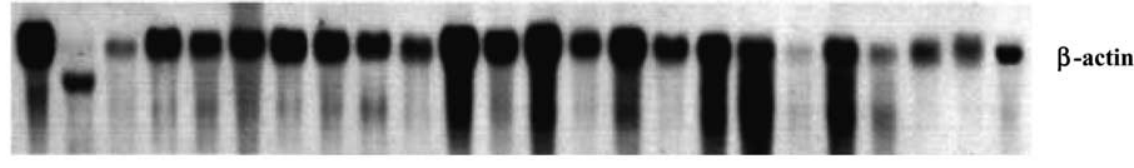

c

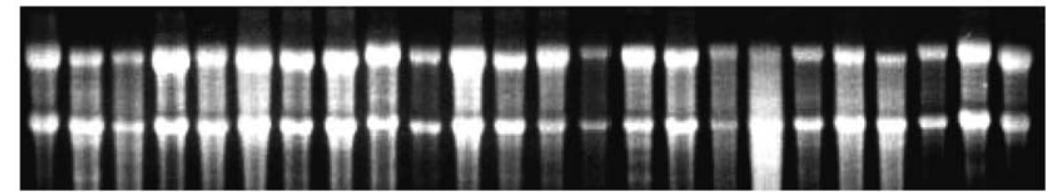

$\begin{array}{llllllllllllllllllllllll}1 & 2 & 3 & 4 & 5 & 6 & 7 & 8 & 9 & 10 & 11 & 12 & 13 & 14 & 15 & 16 & 17 & 18 & 19 & 20 & 21 & 22 & 23 & 24\end{array}$

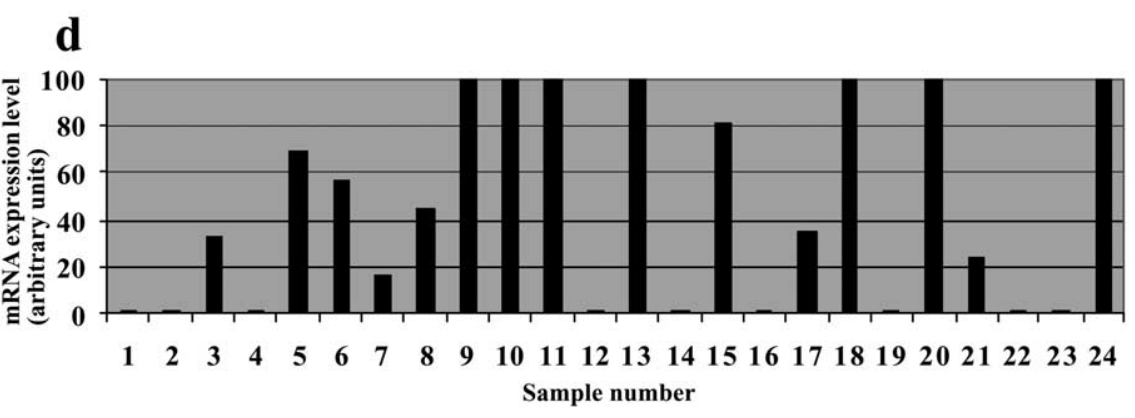

Fig. 1. Expression of HC gp-39 gene in normal human tissues and in brain tumors. (a) Northern blot hybridization of ${ }^{32} \mathrm{P}-\mathrm{labeled} \mathrm{HC}$ gp-39 cDNA probe with tumor RNA panel. Tissue types and tumor subtypes are indicated above each lane of the blot: FB-human fetal brain, He-human heart, K-human kidney, NB-human normal brain, GB-glioblastoma multiforme, AA-anaplastic astrocytoma, A-astrocytoma, OA—oligodendroastrocytoma, Ep—epidermoid, M-meningioma, MS—sarcomatous meningioma. Approximate sizes of HC gp-39 transcripts are indicated on the right side. (b) Northern blot hybridization of the same blot with $\beta$-actin cDNA control probe. (c) Ethidium bromide stained agarose gel. (d) Bar graph showing relative expression of $\mathrm{HC}$ gp-39 gene after correction for gel loading based on $\beta$-actin gene expression.

gene. Increased expression of the HC gp-39 gene was detected in all 20 GBM (WHO grade IV) and in 4 of 15 anaplastic astrocytoma (WHO grade III) samples analyzed. Repeating hybridization of several GBM samples (Fig. 1, lane 9, and Fig. 2, lane 3; Fig. 1, lane 13, and Fig. 2, lane 4; Fig. 1, lane 11, and Fig. 2, lane 5; Fig. 1, lane 15, and Fig. 2, lane 6; Fig. 1, lane 8, and Fig. 2, lane 24) gave same results. Low or undetectable levels of HC gp-39 mRNA were found in samples of normal brain adjacent to glioblastomas and anaplastic astrocytomas and this mRNA was not detectable at all in astrocytomas (WHO grade II) or in adjacent normal brain samples. HC gp-39 mRNA was not detected in other brain tumors: two oligodendroastrocytomas (WHO grade II and WHO grade
II-III), a meningioma (WHO grade II) and a sarcomatous meningioma (WHO grade IV) (Fig. 1), as well as the GBM cell line U251MG (Fig. 2).

In addition to the $1.7 \mathrm{~kb}$ mRNA described previously in human chondrocytes and synovial cells [7], the larger-sized transcript (about $3.0 \mathrm{~kb}$ ) was found preferentially in samples of GBM and anaplastic astrocytoma (Figs. 1 and 2).

\section{Discussion}

Formation and malignant progression of astrocytic tumors are associated with alterations of a variety of genes which can act as a result of mutation, 

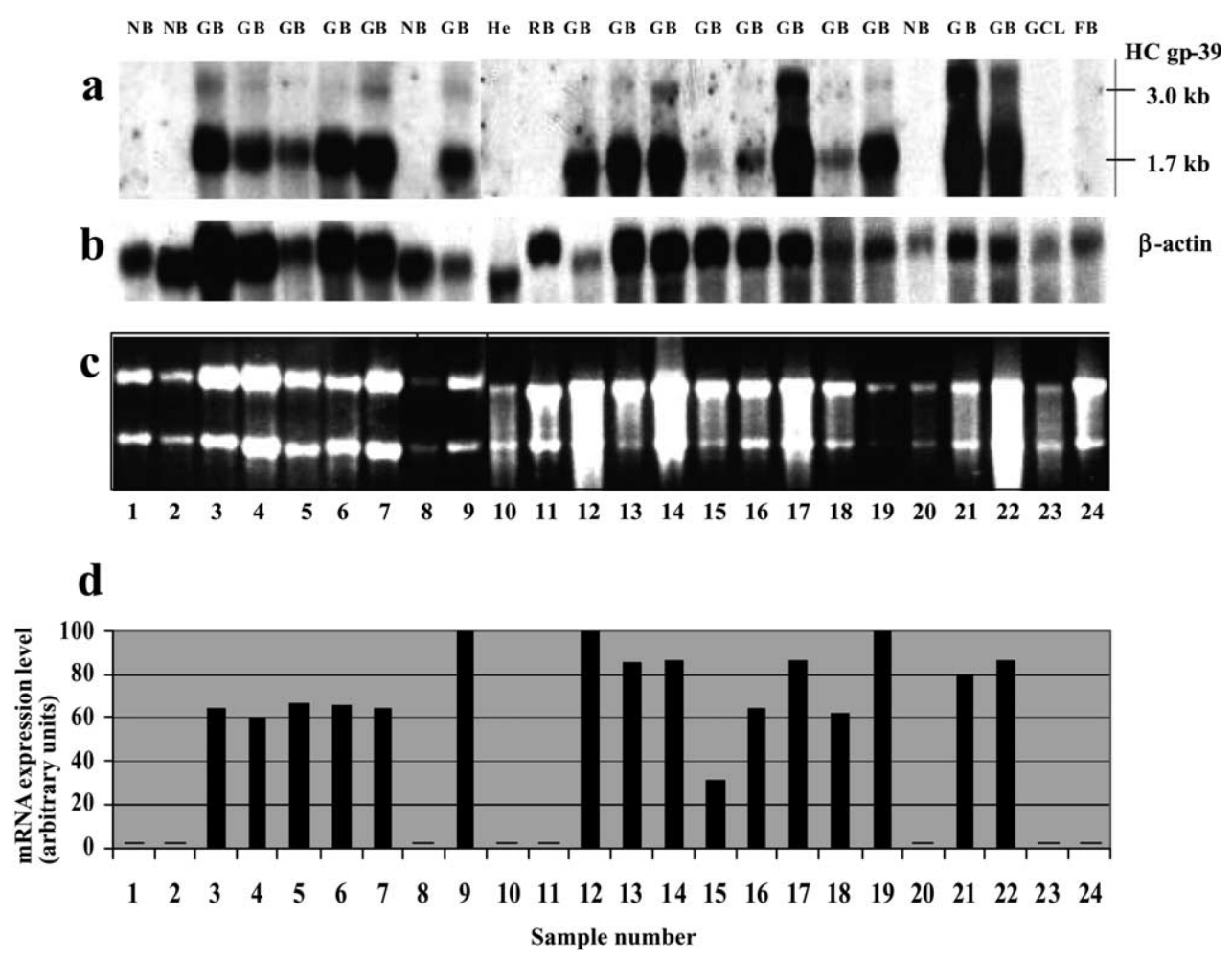

Fig. 2. Expression of HC gp-39 gene in normal tissues and in GBMs. (a) Northern blot hybridization of ${ }^{32} \mathrm{P}-1 \mathrm{abeled} \mathrm{HC}$ gp-39 $\mathrm{cDNA}$ probe with tumor RNA panel. Tissue types and tumor subtypes are indicated above each lane of the blot: NB-human normal brain, GB-glioblastoma multiforme, He—human heart, RB—rat brain, GCL—glioblastoma multiforme cell line U251MG, FB—human fetal brain. Approximate sizes of HC gp-39 transcripts are indicated on the right side. (b) Northern blot hybridization of the same blot with $\beta$-actin cDNA control probe. (c) Ethidium bromide stained agarose gel. (d) Bar graph showing relative expression of HC gp-39 gene after correction for gel loading based on $\beta$ actin gene expression.

e.g. change at the DNA level, such as p53, Rb, EGFR [1], or by modulation at the expression level [3]. The identification of genes of the latter group may yield new molecular markers for diagnostics and targets for treatment of astrocytic gliomas. Suppression subtractive hybridization [8,9], differential display [10], and DNA microarray technology [11] are the most attractive methods for the identification of differentially expressed genes. On the other hand, public accessible databases, such as SAGEmap [6] and Digital Differential Display [12,13], were created as components of CGAP. Any user of these databases can compare the transcript populations between any of the selected libraries, using SAGE and EST analyses.

In this work we report on the differential expression of the HC gp-39 gene, identified by electronic subtraction via the Internet. Overexpression of this gene in astrocytic tumors was confirmed by Northern analysis. Previously it was shown that an increased level of HC gp-39 protein (YKL-40) reflected inflammation or tissue degradation and was found in the serum of patients with rheumatoid arthritis, osteoarthritis [14], hepatic fibrosis [15] and atherosclerosis [16]. The analysis of mRNA distribution in human tissues showed that HC gp-39 is not chondrocyte-specific and that, under normal physiological conditions, the liver could be a major source of this protein [8]. HC gp-39 protein is synthesized also by activated macrophages [16], present in the specific granules of neutrophils and is exocytosed by activation [17]. A high serum HC gp-39 concentration has been found also in patients with colorectal cancer [18] and recurrent breast cancer [19].

Our results extend previous data concerning the role of HC gp-39 in malignant pathologies. Significant 
Table 2

Statistical analysis of HC gp-39 mRNA levels

\begin{tabular}{|c|c|c|c|c|}
\hline Test group & $\begin{array}{l}\text { Mean HC } \\
\text { gp-39 mRNA } \\
\text { level }\end{array}$ & SD & $P$ & $\begin{array}{l}\text { Number } \\
\text { of the } \\
\text { samples }\end{array}$ \\
\hline GBM & 69.9 & 19.9 & $<0.001$ & 20 \\
\hline Normal & 14.0 & 18.0 & & 28 \\
\hline GBM & 69.9 & 19.9 & $<0.001$ & 20 \\
\hline Astrocytoma & 4.1 & 3.5 & & 4 \\
\hline GBM & 69.9 & 19.9 & 0.004 & 20 \\
\hline Other tumors & 15.6 & 30.8 & & 10 \\
\hline Astrocytoma & 4.1 & 3.5 & 0.148 & 4 \\
\hline Normal & 14.0 & 18.0 & & 28 \\
\hline Other tumors & 15.6 & 30.8 & 0.907 & 10 \\
\hline Normal & 14.0 & 18.0 & & 28 \\
\hline Astrocytoma & 4.1 & 3.5 & 0.389 & 4 \\
\hline Other tumors & 15.6 & 30.8 & & 20 \\
\hline $\begin{array}{l}\text { Anaplastic } \\
\text { astrocytoma }\end{array}$ & 23.0 & 38.0 & 0.507 & 15 \\
\hline Normal & 14.0 & 18.0 & & 28 \\
\hline $\begin{array}{l}\text { Anaplastic } \\
\text { astrocytoma }\end{array}$ & 23.0 & 38.0 & 0.198 & 15 \\
\hline Astrocytoma & 4.1 & 3.5 & & 4 \\
\hline $\begin{array}{l}\text { Anaplastic } \\
\text { astrocytoma }\end{array}$ & 23.0 & 38.0 & 0.714 & 15 \\
\hline Other tumors & 15.6 & 30.8 & & 10 \\
\hline $\begin{array}{l}\text { Anaplastic } \\
\text { astrocytoma }\end{array}$ & 23.0 & 38.0 & 0.005 & 15 \\
\hline GBM & 69.9 & 19.9 & & 20 \\
\hline
\end{tabular}

differences (Table 2) were detected between the level of $\mathrm{HC}$ gp-39 mRNA in glioblastomas and control (surgical specimens of histologically normal brain tissue adjacent to tumors), lower-grade astrocytomas $(P<0.001)$ as well as between glioblastomas and other tumors $(P=0.004)$, while no significant difference was detected between lower-grade astrocytomas and control $(P=0.148)$, other tumors and control $(P=0.907)$, and lower-grade astrocytomas and other tumors $(P=0.389)$. The absence of significant differences between anaplastic astrocytomas and control $(P=0.507)$, lower-grade astrocytomas $(P=0.198)$ and other tumors $(P=$ $0.714)$, yet a high difference versus $\operatorname{GBM}(P=$ $0.005)$, was rather surprising. Indeed, the anaplastic astrocytomas compose very a non-uniform group: the level of HC gp-39 mRNA was same as in astrocytomas, WHO grade II, in 11 samples, while in 4 samples of the 15 samples of anaplastic astrocytoma, the level of HC gp-39 mRNA was as high as in GBMs.

It should be pointed out that gene expression in normal brain results from a mixture of glial, neuronal and microglial cells, in addition to endothelial cells and lymphocytes. As with other known tumor markers, differences in gene expression in malignant gliomas are not unexpected. Of course the 'normal' brain tissue collected around the tumor samples may serve as a source of normal adult human brain RNA only with some precautions: gliomas are infiltrating tumors and scattered tumor cells are present far away from the dense tumor area removed during surgery. Moreover, inflammation and astrocytic activation occur in this peritumoral tissue. The differences in the expression of $\mathrm{HC}$ gp-39 are clearly visible when individual samples of normal brain are compared to the mean HC gp-39 mRNA level in GBMs (Fig. 3). Nevertheless, even though this control is not

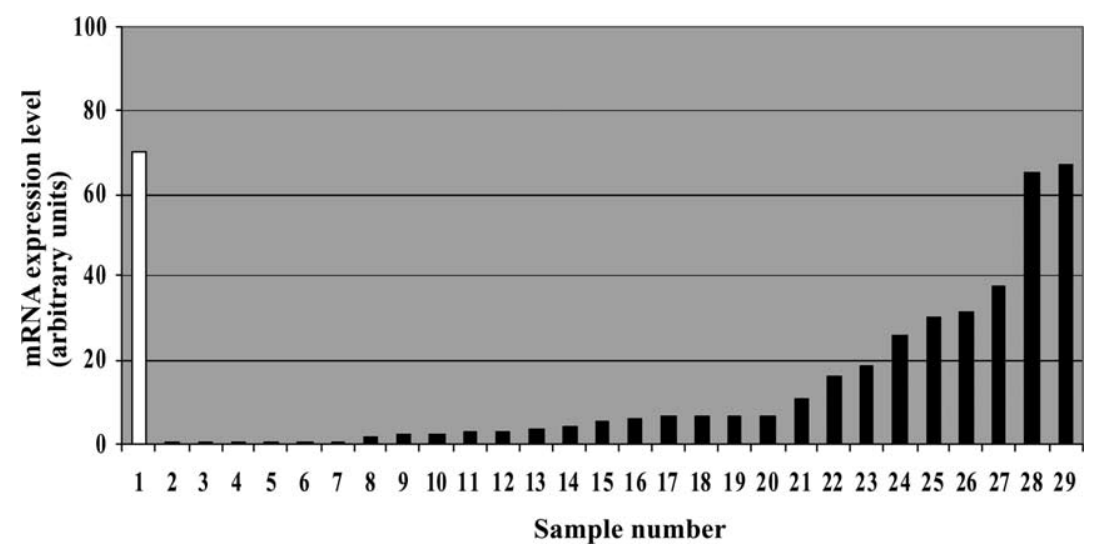

Fig. 3. The differences in the expression of HCgp-39 in normal brain tissue compared to the mean HC gp-39 mRNA level in GBMs. Light column-mean HC gp-39 mRNA level for GBMs (20 samples). Dark columns-HC gp-39 mRNA level for individual samples of normal brain. 
absolutely reliable, increase of $\mathrm{HC}$ gp-39 gene expression was statistically significant. Since neither SAGE nor Northern analysis was able to reveal the presence of $\mathrm{HC}$ gp-39 mRNA in the glioblastoma cell line, the detection of increased quantities of this mRNA in GBMs may be associated with activated macrophages at a late stage of differentiation from blood monocytes [16,20]. Macrophages are key participants in angiogenesis. Immunostaining of macrophages and small vessels in resected glioma specimens allowed Nishie et al. [21] to show that numbers of infiltrating macrophages and small vessel density were higher in glioblastomas than in astrocytomas or anaplastic astrocytomas. Macrophage infiltration was closely correlated with vascular density in human gliomas. In this study the highest level of HC gp-39 gene expression was found mostly in glioblastomas, WHO grade IV, and thus can be used as a molecular marker in the analysis of malignant progression of astrocytic gliomas or for GBM diagnostics.

Angiogenesis is necessary for the continued growth of solid tumors and acceleration of tumor growth accompanies neovascularization [22,23]. Development of blood vessels within tumor tissue is closely correlated with invasion and metastasis, as has been demonstrated in malignant melanoma and cancers of breast, lung, prostate, and other organs $[22,24]$. On the other hand, high HC gp-39 mRNA and protein levels that are found in such different tumors as colorectal cancer [18], recurrent breast cancer (Table 3 and Ref. [19]), and glioblastoma multiforme (this investigation and Ref. [25]) and are related to shorter survival of patients compared to patients with normal levels of HC gp-39, bear witness to the fact that enhanced $\mathrm{HC}$ gp-39 gene expression is common at least for a majority of malignant tumors in their lethal stages. $\mathrm{HC}$ gp-39 apparently plays some role in tumor invasion and may be useful as a marker for macrophage infiltration and neovascularization, as well as a prognostic marker of survival in monitoring patients with advanced cancer.

Larger-sized HC gp-39 transcripts in higher-grade astrocytomas most probably arise from alternative processing by use of an alternative promoter, selection of an alternative splice site or a $3^{\prime}$-polyadenylation signal. These modifications often alter the translation product or regulate mRNA stability. Production of such mRNA is an important feature of high-grade astrocytomas and presumably can be used as an additional factor for distinguishing between astrocytoma (WHO grade II) and anaplastic astrocytoma or between GBM and other types of human brain tumors in the cases of ambiguous histological diagnoses. Previously, Xua et al. [26] found preferential appearance of larger-sized transcripts for several genes in oligodendrogliomas when compared to astrocytomas and meningiomas or non-tumor gray matter. The authors suggested that the formation of larger-sized transcripts may be an important feature for distinguishing between astrocytomas and oligodendrogliomas because multiple sizes of transcripts have not been reported for astrocytomas. Our results show the occurrence of different sizes of transcripts from the HC gp-39 gene in astrocytic gliomas. In addition to $\mathrm{HC}$ gp-39 gene transcripts, we noted also the existence of larger-sized transcripts in higher grade astrocytomas for the ZFM1 gene encoding a transcription/splicing factor, implicated in signal transduction and activation of RNA (data not shown). Thus, these data are in contradiction to the suggestion of Xua et al. [26] and the phenomenon of multiple size transcripts is not limited only to oligodendrogliomas but also takes place in other types of brain tumors.

Table 3

Distribution of the Hs.75184 (GTATGGGCCC) tag for HC gp-39 gene within human mammary gland tumor SAGE libraries

\begin{tabular}{llrr}
\hline Library name & Source & Tags per million & Tag counts \\
\hline GSM741: SAGE_PTEN & Mammary gland carcynoma_cell line & 106 & 1 \\
GSM2389: SAGE_DCIS-3 & Mammary gland ductal in situ high grade carcinoma & 51 & 9394 \\
GSM1733: SAGE_IDC-3 & Mammary gland ductal invasive in situ low grade carcinoma & 14 & 3 \\
GSM2382: SAGE_IDC-4 & Mammary gland ductal invasive high grade carcinoma & 2321 & 1 \\
GSM2383: SAGE_IDC-5 & Mammary gland ductal invasive low grade carcinoma & 16 & 70,099 \\
\hline
\end{tabular}




\section{Acknowledgements}

This work was supported in part by NATO Collaborative Linkage Grant No. 977284.

\section{References}

[1] D.N. Louis, A molecular genetic model of astrocytoma histopathology, Brain Pathol. 7 (1997) 755-764.

[2] J.S. Smith, R.B. Jenkins, Genetic alterations in adult diffuse glioma: occurrence, significance, and prognostic implications, Front Biosci. 5 (2000) D213-D231.

[3] L. Zhang, W. Zhou, V.E. Velculescu, S.E. Kern, R.H. Hruban, S.R. Hamilton, B. Vogelstein, et al., Gene expression profiles in normal and cancer cells, Science 276 (1997) $1268-1272$.

[4] R. Sager, Expression genetics in cancer: shifting the focus from DNA to RNA, Proc. Natl Acad. Sci. USA 94 (1997) 952-955.

[5] P. Chomczynski, N. Sacchi, Single-step method of RNA isolation by acid guanidinium thiocyonate-phenol-chloroform extraction, Anal. Biochem. 162 (1987) 156-159.

[6] A. Lal, A.E. Lash, S.F. Altschul, V.E. Velculescu, L. Zhang, R.E. McLendon, A public database for gene expression in human cancers, Cancer Res. 59 (1999) 5403-5407.

[7] B.E. Hakala, C. White, A.D. Recklies, Human cartilage gp-39, a major secretory product of articular chondrocytes and synovial cells, is a mammalian member of a chitinase protein family, J. Biol. Chem. 268 (1993) 25803-25810.

[8] L. Diatchenko, Y.-F. Lau, A.P. Campbell, A. Chenchik, F. Moqadam, B. Huang, et al., Supression subtractive hybridization: a method for generating differentially regulated or tissue-specific probes and libraries, Proc. Natl Acad. Sci. USA 93 (1996) 6025-6030.

[9] O.D. von Stein, W.-G. Thies, M. Hofmann, A high throughput screening for rarely transcribed differentially expressed genes, Nucl. Acid Res. 25 (1997) 2598-2602.

[10] P. Liang, A.B. Pardee, Differential display of eukaryotic messenger RNA by means of the polymerase chain reaction, Science 257 (1992) 967-971.

[11] M. Schena, D. Shalon, R.W. Dawis, P.O. Brown, Quantitative monitoring of gene expression patterns with a complementary DNA array, Science 270 (1995) 467-470.

[12] K. Okubo, N. Hori, R. Matoba, T. Niiyama, A. Fukushima, Y. Kojima, K. Matsubara, Large scale cDNA sequencing for analysis of quantitative and qualitative aspects of gene expression, Nat. Genet. 2 (1992) 173-179.

[13] D. Scheurle, M.P. DeYoung, D.M. Binninger, H. Page, M. Jahanzeb, R. Narayanan, Cancer gene discovery using Digital Differential Display, Cancer Res. 60 (2000) 4037-4043.
[14] B. Volck, J.S. Johansen, M. Stoltenberg, C. Garbarsch, P.A. Price, M. Ostergaard, et al., Studies on YKL-40 in knee joints of patients with rheumatoid arthritis and osteoarthritis. Involvement of YKL-40 in the joint pathology, Osteoarthritis Cartilage 9 (2001) 203-214.

[15] J.S. Johansen, P. Christoffersen, S. Moller, P.A. Price, J.H Henriksen, C. Garbarsch, F. Bendtsen, Serum YKL-40 is increased in patients with hepatic fibrosis, J. Hepatol. 32 (2000) 911-920.

[16] R.G. Boot, T.A. van Achtenberg, B.E. van Aken, G.H. Renkema, M.J. Jacobs, J.M. Aerts, C.J. de Vries, Strong induction of members of the chitinase family of proteins in atherosclerosis: chitotriosidase and human cartilage gp-39 expressed in lesion macrophages, Arterioscler. Thromb. Vasc. Biol. 19 (1999) 687-694.

[17] B. Volck, P.A. Price, J.S. Johansen, O. Sorensen, T. Benfield, H.G. Nielsen, J. Calafat, et al., YKL-40, a mammalian member of the bacterial chitinase family, is a matrix protein of specific granules in human neutrophils, Proc. Assoc. Am. Phys. 110 (1998) 351-360.

[18] C. Cintin, J.S. Johansen, I.J. Christensen, P.A. Price, S Sorensen, H.J. Nielsen, Serum YKL-40 and colorectal cancer, Br. J. Cancer 79 (1999) 1494-1499.

[19] J.S. Johansen, C. Cintin, M. Jorgensen, C. Kamby, P.A. Price, Serum YKL-40: a new potential marker of prognosis and location of metastases of patients with recurrent breast cancer, Eur. J. Cancer 31A (1995) 1437-1442.

[20] S.W. Krause, M. Rehli, M. Kreutz, L. Schwarzfischer, J.D Paulauskis, R. Andreesen, Differential screening identifies genetic markers of monocyte to macrophage maturation, J. Leukoc. Biol. 60 (1996) 540-545.

[21] A. Nishie, M. Ono, T. Shono, J. Fukushi, M. Otsubo, H. Onoue, et al., Macrophage infiltration and heme oxygenase-1 expression correlate with angiogenesis in human gliomas, Clin. Cancer Res. 5 (1999) 1107-1113.

[22] I.J. Fidler, L.M. Ellis, The implications of angiogenesis for the biology and therapy of cancer metastasis, Cell 79 (1994) $185-188$

[23] J. Folkman, K. Watson, D. Ingber, D. Hanahan, Induction of angiogenesis during the transition from hyperplasia to neoplasia, Nature 339 (1989) 58-61.

[24] N. Weidner, J.P. Semple, W.R. Welch, J. Folkman, Tumor angiogenesis and metastasis: correlation in invasive breast carcinoma, N. Engl. J. Med. 324 (1991) 1-8.

[25] M. Tanwar, M.R. Gilbert, E.C. Holland, Gene expression microarray analysis reveals YKL-40 to be a potential serum marker for malignant character in human glioma, Cancer Res. 62 (2002) 4364-4368.

[26] X. Xua, H.D. Johb, S. Pinb, N.I. Schillera, C. Prangec, P.C. Burgera, M.R. Schiller, Expression of multiple largersized transcripts for several genes in oligodendrogliomas: potential markers for glioma subtype, Cancer Lett. 171 (2001) 67-77. 